\title{
A coronary care unit in a general medical ward
}

\author{
J. D. Eddy ${ }^{1}$ and J. Mackinnon ${ }^{2}$ \\ From The Department of Cardiology, Dudley Road Hospital, Birmingham I8
}

In all, 6 I I patients were admitted to the coronary care unit during the first I6 months. The diagnosis of acute myocardial infarction was confirmed in $461(73.4 \%)$ of these patients and the results of treatment are shown.

The hospital mortality was I9.I per cent. Eighteen patients, who would have died without resuscitation, survived and left hospital. Ventricular fibrillation occurred in $4 I$ ( $8.9 \%$ ) patients, early resuscitation was successful in 23, and I4 left hospital. Asystole was the cause of cardiac arrest in $3 I(6.7 \%)$ patients, most of whom had extensive heart muscle damage and failure. Resuscitation was unusual in these patients. Complete heart block occurred in $3 I(6.7 \%)$ patients and all were electrically paced. Sixteen returned to sinus rhythm and I4 left hospital. No patients required long-term pacing after acute myocardial infarction. Ventricular tachycardia occurred in $45(9.7 \%)$ patients and this arrhythmia carried a high mortality (46.6\%).

Our results appear to be comparable with those of most other units, many of which are considerably more elaborate in design and more heavily staffed.

There are disadvantages to siting a coronary care unit in a general ward and, though good results can be achieved in a unit of this type, we think it desirable that separate accommodation should be found whenever possible. This has now been done at Dudley Road Hospital.

Acute myocardial infarction is the most important cause of the high mortality in coronary heart disease, and it has been shown (Julian, Valentine, and Miller, 1964; Fluck et al., 1967; McNeilly and Pemberton, 1968) that a major proportion of deaths occurs in the first 48 hours after infarction from arrhythmias. For this reason, coronary care units have been developed where the prompt recognition and treatment of dangerous arrhythmias may be carried out without delay. Reports (Restieaux et al., I967; Thomas, Jewitt, and Shillingford, 1968; Pentecost and Mayne, 1968) suggest that a significant reduction of mortality can be achieved in such units. In some hospitals it may be difficult to allocate separate accommodation to units of this kind, and in Dudley Road Hospital no suitable accommodation was available. We therefore adapted part of a general medical ward as a coronary care unit and report our first I6 months' experience.

Received 17 February 1970.

1 Present address: Good Hope General Hospital, Sutton Coldfield, Warwicks.

2 Address for reprints: Dr. J. Mackinnon, Consultant Cardiologist, Dudley Road Hospital, Birmingham 18.

\section{Description of unit}

Six beds on one side of the proximal end of a 33bedded general medical ward were adapted for coronary care. Two beds from the medical ward were sacrificed to give extra space for the coronary unit. An area of I Io square feet was available for each bed and this allowed reasonable space for resuscitation procedures to be carried out. Each bed was wired to provide access to 6 power outlets and equipped with a wall-mounted sphygmomanometer, piped oxygen, and suction. Curtains were provided to screen each bed from the others when desired. A trolley-mounted oscilloscope (Cardiorater, Cardiac Recorders) was available for each bed, and a central multichannel display oscilloscope was placed in the nursing station. Permanent electrocardiogram readings were made with a single channel recorder. The beds used were General Purpose Hospital Beds (NesbitEvans) with firm base, foam rubber mattress, and detachable head and foot. The height of the bed was easily adjustable and it could be tilted. Patients of either sex brought to the hospital with a diagnosis of acute myocardial infarction within the preceding 72 hours were admitted to the unit, monitored for 72 hours, and then transferred to beds on the general medical wards. Complicated cases were kept longer in the unit. The patients were nursed by staff entirely separate from the staff of the general ward, and the unit day staff consisted of 2 sisters, 2 staff nurses, and a state enrolled nurse. At night, one sister and one staff 
nurse were on duty. Throughout the period of admission each patient remained under the care of his own consultant physician and that consultant's junior staff, but cardiac pacemaking and other special procedures were undertaken by a member of the cardiac department of the hospital. There was no resident doctor in the unit. An alarm system was available to summon the hospital cardiac arrest team, together with a member of the cardiac department and a cardiological technician for emergencies. A DC defibrillator, pacemakers, anaesthetic trolley, and an emergency drug trolley were kept in the unit. A portable image intensifier was also available for insertion of electrodes for cardiac pacing in the unit.

\section{Patients and management}

In the 16 months since the opening of the unit 6 I I patients were admitted, of whom 46 I $(75.4 \%)$ were shown to have had acute myocardial infarctions. There were 349 men (average age-57 years) and II 2 women (average age-6I years). Details of age and sex are shown in Fig. I and the duration of acute symptoms before admission in Fig. 2.

The diagnosis of acute myocardial infarction was made on a characteristic history together with the electrocardiographic changes described by the World Health Organization (1959) and/or a rise of serum enzymes (aspartate aminotransferase and lactic dehydrogenase), and the results include only patients fulfilling these diagnostic criteria. Patients were unselected. Continuous oxygen and anticoagulants were not used routinely; this treatment depended on the physician in charge of individual patients. An intravenous infusion was not used routinely, though it was found necessary in approximately 50 per cent of patients either for administration of drugs or measurement of central venous pressure. Digoxin and diuretics were used for the treatment of heart failure or if radiological evidence of pulmonary congestion was present.

Intravenous lignocaine was administered according to the routine of Lown et al. (1967), for any type of ectopic beats meeting the following criteria.

i) The occurrence of more than 6 ectopic beats a minute.

ii) Ectopic beats occurring during the 'vulnerable' period of the preceding beat.

iii) The occurrence of multifocal ectopic beats.

Ventricular tachycardia was treated initially with intravenous lignocaine. If sinus rhythm were not quickly restored, DC countershock was administered under light intravenous anaesthesia. Ventricular fibrillation was treated with immediate DC countershock. No treatment was given for first and second degree heart block, but the development of complete heart block was treated by the immediate insertion into the right ventricle of a bipolar endocardial pacemaker catheter through an antecubital vein. The catheter was left in position for 6 days after the return of sinus rhythm.

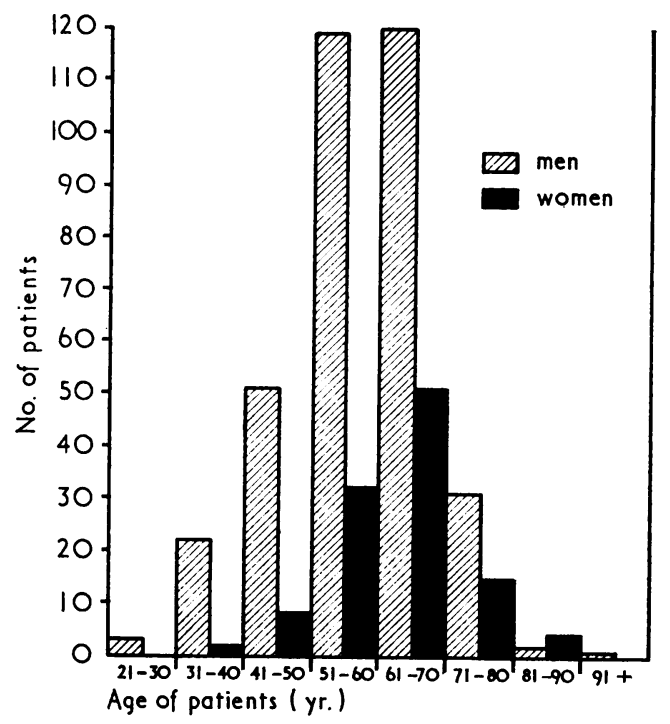

FI I. I Age and sex of $46 I$ patients with acute myocardial infarction.

FIG. 2 Duration of acute symptoms in $46 I$ patients with acute myocardial infarction before admission.

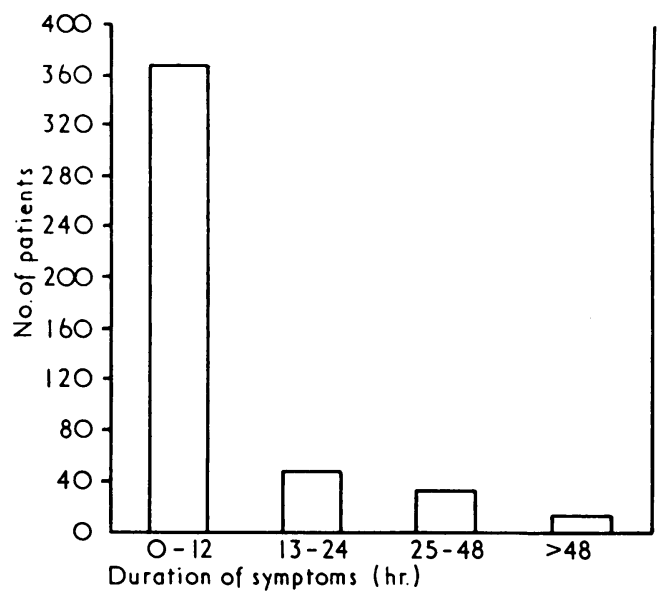

\section{Results}

The mortality rate for the period of admission to hospital was I9.I per cent and the mortality in the unit was 13.7 per cent. The relation between age, sex, and mortality is shown in Fig. 3.

The frequency of arrhythmias is shown in Table I. It is probable that transient arrhythmias were more frequent and unnoticed, as facilities were not available for continuous recording of heart rhythm. Atrial fibrillation occurred in $66(14.3 \%)$ patients. Forty-five $(9.7 \%)$ developed ventricular tachycardia and 
TABLE I Incidence of arrhythmias in $46 \mathrm{I}$ patients with acute myocardial infarction

\begin{tabular}{lrr}
\hline Rhythm & No. of patients & $\%$ \\
\hline Ventricular extrasystoles & 265 & $57 \cdot 5$ \\
Atrial fibrillation & 66 & $14 \cdot 3$ \\
Ventricular tachycardia & 45 & $9 \cdot 7$ \\
Ventricular fibrillation & $4 \mathrm{I}$ & $8 \cdot 9$ \\
Complete heart block & $3 \mathrm{I}$ & $6 \cdot 7$ \\
Paroxysmal tachycardia & 6 & $1 \cdot 3$ \\
& & \\
\hline
\end{tabular}

TABLE 2 Cardiac arrest in 72 patients

\begin{tabular}{llll}
\hline & $\begin{array}{l}\text { No. of } \\
\text { patients }\end{array}$ & $\begin{array}{l}\text { Early } \\
\text { survival }\end{array}$ & $\begin{array}{l}\text { Late } \\
\text { survival }\end{array}$ \\
\hline $\begin{array}{l}\text { Primary ventricular } \\
\text { fibrillation }\end{array}$ & 14 & 14 & $12(86 \%)$ \\
$\begin{array}{l}\text { Secondary ventricular } \\
\text { fibrillation }\end{array}$ & 27 & 9 & $2(7 \%)$ \\
$\begin{array}{l}\text { Asystole } \\
\text { Syl }\end{array}$ & 31 & 4 & $4(13 \%)$ \\
\hline
\end{tabular}

2 I $(46.6 \%)$ died. Complete heart block developed in $31(6.7 \%)$ patients aged $38-84$ (average age-6r $\cdot 9$ ). All were electrically paced, and 16 returned to sinus rhythm, usually within 72 hours. Fourteen $(45 \cdot 1 \%)$ of these patients survived and were discharged. Thus, 17 patients who developed complete heart block died and the mortality was 54.9 per cent for this group.

Cardiac arrest occurred in 72 patients and the cause and results of treatment are shown in Table 2.

Cardiac arrest was due to asystole in 31 patients and $27(81 \%)$ died. The majority of these patients had cardiogenic shock syndrome or heart failure.

Ventricular fibrillation occurred in $4 \mathrm{I}$ patients $(8.9 \%)$, and 14 of these were cases of primary ventricular fibrillation. All I4 were initially successfully resuscitated, but 2 subsequently died.

Ventricular fibrillation was secondary to heart failure or shock in 27 patients. Eighteen of these patients died, and in 9 sinus rhythm was initially restored but subsequently 7 died; thus, only 2 of the 27 patients with secondary ventricular fibrillation survived to leave hospital.

The total survival rate for both types of ventricular fibrillation was $34 \cdot \mathrm{I}$ per cent, with 86 per cent survival in cases of primary ventricular fibrillation and 7 per cent survival in cases of secondary fibrillation.

\section{Discęssion}

The inortality rate $(19 \cdot 1 \%)$ of our first 461

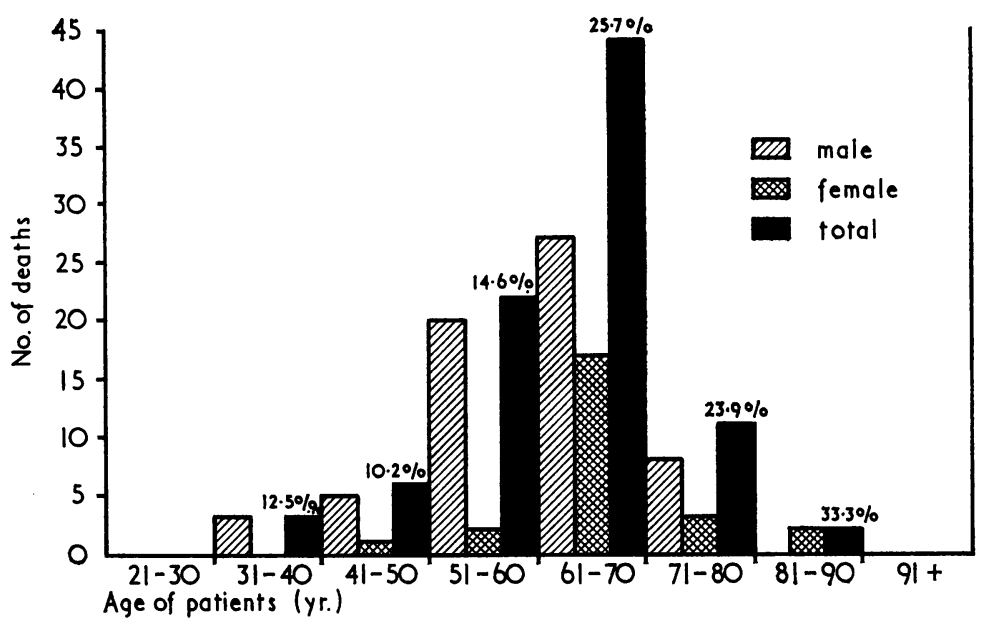

FIG. 3 Age, sex, and mortality in $46 \mathrm{I}$

patients with acute myocardial infarction.

patients compares favourably with the experience in other coronary care units (Fluck et al., 1967; Lawrie et al., 1967; Pentecost and Mayne, 1968). Our figures show a high proportion of admissions shortly after the onset of symptoms, and $366(79.3 \%)$ patients were admitted within 12 hours. The incidence of ventricular fibrillation $(8.9 \%)$ occurring within the unit was very similar to other units (Restieaux et al., 1967; Pentecost and Mayne, I968; Julian et al., 1964). Thirty-four per cent of these cases survived to be discharged from hospital: this was made up of 86 per cent of the cases of primary ventricular fibrillation and 7 per cent of the cases of secondary fibrillation.

This survival rate is similar to that in other units (Restieaux et al., 1967; Pentecost and Mayne, 1968), and we agree with these authors that immediate defibrillation offers the best chance of reversion to normal rhythm without delaying for intubation or other procedures.

Ventricular extrasystoles were the commonest arrhythmia in our patients $(57.5 \%)$, but the true incidence was almost certainly higher than this, as shown by units where the electrocardiogram was continuously recorded. Supraventricular arrhythmias were common (15.6\%), but paroxysmal tachycardia was observed in only 6 patients. This finding is at variance with the experience of Jewitt $e t$ al. (1967) but is similar to the incidence reported by Pentecost and Mayne (1968). This finding could again be due to inadequate recording in our patients.

The reported incidence of ventricular tachycardia varies considerably; thus, Lawrie 
et al. (1967) reported an incidence of 15 per cent, Pentecost and Mayne (1968) 6 per cent, and Aber, Portal, and Chopra (1969) 0.2 per cent. Forty-five $(9 \cdot 7 \%)$ of our patients developed this arrhythmia and it was associated with a high mortality $(46.6 \%)$. This was because it frequently occurred in patients with heart failure and appeared to precede cardiac arrest.

Complete heart block occurred in $31(6.7 \%)$ of our patients (average age-6r.9), and this incidence was similar to the experience of others (Restieaux et al., 1967; Aber et al., 1969; Pentecost and Mayne, 1968). All patients with complete heart block were electrically paced using an on demand pacemaker system and I6 returned to sinus rhythm, usually within 72 hours. Fourteen $(45.1 \%)$ of these patients survived and were discharged from hospital. Thus, 17 patients who developed complete heart block died, and the mortality was 54.9 per cent for this group. No patient required permanent pacing after an acute infarct. Complete heart block was frequently a sudden occurrence without warning and was associated with sudden deterioration of the patient's condition. The rapid insertion of a pacing electrode through an antecubital vein was undertaken in the unit with the aid of a portable image intensifier. The majority of patients showed rapid clinical improvement after pacing was established, but the eventual outcome depended on the extent of heart muscle damage. The electrode was left in position for 6 days after return to sinus rhythm.

Asystole was the cause of cardiac arrest in 3I $(6.7 \%)$ patients, and only $4(13 \%)$ survived. Two of these probably owe their survival to immediate resuscitative measures by the nursing staff. There were 27 deaths in this group, a mortality of 87 per cent. Asystole appeared to occur usually in patients who had suffered either heart failure or cardiogenic shock, and extensive heart muscle damage was often present.

Our results appear to be comparable with those of most other units, many of which were considerably more elaborate in design and equipment and more heavily staffed. This was a simple unit in a general medical ward, in which patients were under the care of their own physician with help when necessary from members of the cardiac department. The modification of the ward and purchase of equipment was relatively inexpensive. The unit had its own nursing staff, which was quite separate from that of the main ward, and this necessitated two nursing stations within the ward, with separate internal and external telephone lines. We consider this division of nursing staff most important, for we believe that the two most important factors in the unit's success were the skill and devotion of the nursing and junior medical staff. There were occasions when the presence of a resident doctor in the unit would have been an advantage, but this was not possible with the present staffing structure. Mixing the sexes caused no problems and the majority of patients accepted this situation without comment. This was probably because patients were often ill and confined to bed and very good screening was available. Unlike Reynell (1969), we found certain disadvantages in siting the unit in a busy ward. When cardiac arrest or other emergency occurred in the unit at night noise was unavoidable and inevitably resulted in disturbance of the ward patients. Conversely, an emergency in the general ward caused disturbance to patients in the unit. As the unit was sited at the proximal end of the ward, all visitors and other traffic to the main ward passed through the unit, causing unavoidable noise and disturbance to patients in it.

Space in the unit was necessarily limited to avoid sacrificing more than 2 medical beds and this resulted in inadequate storage space for bulky items of equipment, such as the image intensifier, lead aprons, and anaesthetic trolley. Space for special procedures, such as $x$-ray screening for the insertion of pacemaking electrodes and carrying out haemodynamic measurements, was also restricted. We consider that these were major disadvantages to the comfort and care of patients in both the coronary care unit and the main ward, and were of sufficient importance to recommend the allocation of separate accommodation to coronary care units whenever possible. We believe that, though good results were achieved in our unit and that, where no suitable separate accommodation is available, this system should be used, it is desirable that coronary care units should have separate accommodation whenever possible. This should be in close proximity to the medical wards, and there may be considerable advantage in linking coronary care and intensive care units, where nursing staff and certain expensive items of equipment can be shared.

We thank the physicians of Dudley Road Hospital for their unanimous support in the development of the unit and for allowing us to include their patients in this report. We are indebted to the junior medical staff, the sisters and nurses of the unit, Miss Gillian Plant and the cardiological technicians for their unstinting help and interest in this work. 


\section{References}

Aber, C. P., Portal, R. W., and Chopra, M. P. (1969). Cardiac monitoring in a regional hospital. British Medical fournal, r, 209.

Fluck, D. C., Olsen, E., Pentecost, B. L., Thomas, M., Fillmore, S. J., Shillingford, J. P., and Mounsey, J. P. D. (1967). Natural history and clinical significance of arrhythmias after acute cardiac infarction. British Heart fournal, 29, 170.

Jewitt, D. E., Balcon, R., Raftery, E. B., and Oram, S. (I967). Incidence and management of supraventricular arrhythmias after acute myocardial infarction. Lancet, 2, 734.

Julian, D. G., Valentine, P. A., and Miller, G. G. (I964). Disturbances of rate, rhythm and conduction in acute myocardial infarction. American fournal of Medicine, 37, 915.

Lawrie, D. M., Greenwood, T. W., Goddard, M., Harvey, A. C., Donald, K. W., Julian, D. G., and Oliver, M. F. (1967). A coronary-care unit in the routine management of acute myocardial infarction. Lancet, 2, 109.

Lown, B., Fakhro, A. M., Hood, W. B., and Thorn,
G. W. (1967). The coronary care unit. New perspectives and directions. Fournal of the American Medical Association, 199, 188.

McNeilly, R. H., and Pemberton, J. (1968). Duration of last attack in 998 fatal cases of coronary artery disease and its relation to possible cardiac resuscitation. British Medical fournal, 3, 139.

Pentecost, B. L., and Mayne, N. M. C. (I968). Results of a general hospital coronary care service. British Medical Fournal, $1,830$.

Restieaux, N., Bray, C., Bullard, H., Murray, M., Robinson, J., Brigden, W., and McDonald, L. (1967). One hundred and fifty patients with cardiac infarction treated in a coronary unit. Lancet, I, 1285.

Reynell, P. C. (1969). Coronary care unit in a general medical ward. British Medical fournal, 2, 502.

Thomas, M., Jewitt, D. E., and Shillingford, J. P. (1968). Analysis of 150 patients with acute myocardial infarction, admitted to an intensive care and study unit. British Medical fournal, I, 787.

World Health Organization (1959). Hypertension and Coronary Heart Disease: Classification and Criteria for Epidemiological Studies. World Health Organization. Technical Report Series, No. I68. 